\title{
HMT-Controlled Synthesis of Mesoporous NiO Hierarchical Nanostructures and Their Catalytic Role towards the Thermal Decomposition of Ammonium Perchlorate
}

\author{
Songzhong Ye and Xiangfeng Guan * \\ Organic Optoelectronics Engineering Research Center of Fujian's Universities, Fujian Jiangxia University, \\ Fuzhou 350108, China \\ * Correspondence: xfguan@fjjxu.edu.cn; Tel.: +86-591-2353-1652
}

Received: 31 May 2019; Accepted: 25 June 2019; Published: 27 June 2019

\begin{abstract}
In this work, mesoporous nickel oxide (NiO) hierarchical nanostructures were synthesized by a facile approach by hydrothermal reaction and subsequent calcination. The phase structure, microstructure, element composition, surface area, and pore size distribution of the as-prepared products were characterized by X-ray diffraction (XRD), scanning electron microscopy (SEM), X-ray photoelectron spectroscopy (XPS), and the Brunauer-Emmett-Teller (BET) technique. The precursor of $\mathrm{Ni}_{3}\left(\mathrm{NO}_{3}\right)_{2}(\mathrm{OH})_{4}$ nanosheet, $\mathrm{Ni}_{3}\left(\mathrm{NO}_{3}\right)_{2}(\mathrm{OH})_{4}$ microsphere, and $\mathrm{Ni}\left(\mathrm{HCO}_{3}\right)_{2}$ sub-microsphere was obtained by hydrothermal reaction at $160^{\circ} \mathrm{C}$ for $4 \mathrm{~h}$ when the ratio of $\mathrm{Ni}^{2+} / \mathrm{HMT}$ (hexamethylenetetramine) was $2: 1,1: 2$, and 1:3, respectively. After calcination at $400{ }^{\circ} \mathrm{C}$ for $2 \mathrm{~h}$, the precursors were completely transformed to mesoporous $\mathrm{NiO}$ hierarchical nanosheet, microsphere, and sub-microsphere. When evaluated as additives of the thermal decomposition of ammonium perchlorate (AP), these $\mathrm{NiO}$ nanostructures significantly reduce the decomposition temperature of $\mathrm{AP}$, showing obvious catalytic activity. In particular, $\mathrm{NiO}$ sub-microsphere have the best catalytic role, which can reduce the high temperature decomposition (HTD) and low temperature decomposition (LTD) temperature by 75.2 and $19.1{ }^{\circ} \mathrm{C}$, respectively. The synthetic approach can easily control the morphology and pore structure of the $\mathrm{NiO}$ nanostructures by adjusting the ratio of $\mathrm{Ni}^{2+} / \mathrm{HMT}$ in the reactants and subsequent calcination, which avoids using expensive templates or surfactant and could be intended to prepare other transition metal oxide.
\end{abstract}

Keywords: HMT-controlled synthesis; NiO; mesopores; hierarchical nanostructures; catalytic activity

\section{Introduction}

Mesoporous metal oxide $\mathrm{MO}(\mathrm{M}=\mathrm{Ni}, \mathrm{Cu}, \mathrm{Zn}$, etc. $)$ materials have attracted much attention due to their large pore volume, high specific surface area, large number of surface reactive sites, and rich material transport channels [1]. Accordingly, these materials are widely applied in many important fields. Among them, nickel oxide $(\mathrm{NiO})$ is an important semiconductor functional material [2], which is widely used in lithium ion batteries [3], electrocatalysis [4], thermal catalysis [5], gas sensor [6], electrochemistry [7,8], optical sensor [9] and biosensors [10-14] fields. Therefore, the preparation of various mesoporous $\mathrm{NiO}$ nanomaterials has become a research hotspot.

$\mathrm{Up}$ to date, researchers have tried to synthesize mesoporous $\mathrm{NiO}$ materials by various synthetic methods, with an aim to improve the properties of materials by optimizing porous nanostructures. For instance, Liu et al. [15] synthesized porous $\mathrm{NiO}$ hierarchical microflowers with improved $\mathrm{H}_{2} \mathrm{~S}$ gas sensing properties. Zhou et al. [16] prepared hierarchical $\mathrm{NiO}$ nanoflakes using polyvinylpyrrolidone as a surfactant, which exhibited enhanced gas sensing properties for $\mathrm{CH}_{4}$ detection. Ahirwar et al. [17] 
developed a sol-gel method to prepare porous $\mathrm{NiO}$ nanostructures using Tween-80 as a non-ionic surfactant and demonstrated excellent photocatalysis and sensing properties. Zhang et al. [18] reported $\mathrm{NiO}$ hierarchical flower-like nanostructures prepared by the solvothermal method, in which cetyltrimethylammonium bromide was used as a surfactant. Han et al. [19] synthesized hierarchical $\mathrm{NiO}$ tremella-like and pinecone-like microspheres by the solvothermal method. The $\mathrm{NiO}$ microspheres demonstrated good supercapacitor properties. Cai et al. [20] used $\alpha-\mathrm{Ni}(\mathrm{OH})_{2}$ as a precursor to prepare chrysanthemum-like $\mathrm{NiO}$ microspheres which exhibited superior lithium storage properties. Hong et al. [21] prepared porous $\mathrm{NiO}$ hierarchical microtubes by a novel template-free method, which exhibited superior electrochemical performance due to their high surface area and pore volume.

Although some progress has been made, most of the reported methods require surfactants or templates, and thus it is difficult to obtain mesoporous $\mathrm{NiO}$ hierarchical materials with multi-morphologies and controllable pore structure. Therefore, it is highly desirable to develop a facile approach to mesoporous $\mathrm{NiO}$ hierarchical materials with multi-morphologies.

In this paper, we developed a rapid and easy approach to mesoporous $\mathrm{NiO}$ hierarchical nanostructures by hydrothermal reaction and subsequent calcination. By adjusting the ratio of $\mathrm{Ni}^{2+} / \mathrm{HMT}$ (hexamethylenetetramine) in a hydrothermal reaction, the precursors of $\mathrm{Ni}_{3}\left(\mathrm{NO}_{3}\right)_{2}(\mathrm{OH})_{4}$ nanosheet, $\mathrm{Ni}_{3}\left(\mathrm{NO}_{3}\right)_{2}(\mathrm{OH})_{4}$ microsphere, and $\mathrm{Ni}\left(\mathrm{HCO}_{3}\right)_{2}$ sub-microsphere were prepared, which transformed to mesoporous $\mathrm{NiO}$ nanosheets, microspheres, and sub-microspheres by simple calcination. These mesoporous $\mathrm{NiO}$ nanostructures can effectively reduce the thermal decomposition temperature of ammonium perchlorate (AP), thereby indicating the potential application as additives for AP thermal decomposition. The approach reported here could be intended to prepare other transition metal oxide.

\section{Materials and Methods}

\subsection{Synthesis of $\mathrm{NiO}$ Nanostructures}

The precursor was prepared by the hydrothermal method which can transform to $\mathrm{NiO}$ by subsequent calcination. In the experiments, nickel chloride hexahydrate puratrem $\left(\mathrm{Cl}_{2} \mathrm{H}_{12} \mathrm{NiO}_{6}\right.$, Sinopharm Chemical Reagent Co., Ltd., Shanghai, China) and HMT $\left(\mathrm{C}_{6} \mathrm{H}_{12} \mathrm{~N}_{4}\right.$, Sinopharm Chemical Reagent Co., Ltd., Shanghai, China) were used as raw materials, and deionized water as reaction solvent. The experimental process was as follows: $\mathrm{Cl}_{2} \mathrm{H}_{12} \mathrm{NiO}_{6}$ was firstly dissolved in deionized water to get $0.2 \mathrm{M} \mathrm{Ni}^{2+}$ solution, and then HMT was added the solution under stirring to obtain the mixed solution. The mixed solution was then transferred to the stainless-steel autoclave at $160^{\circ} \mathrm{C}$ for $4 \mathrm{~h}$ to obtain the precursor product. Among them, the molar ratios of $\mathrm{Ni}^{2+} / \mathrm{HMT}$ were 2:1, 1:2, and 1:3 for the synthesis of nickel oxide precursor nanosheets, microspheres, and sub-microspheres, respectively. After being cleaned and dried, the as-prepared precursors were put into a high-temperature furnace and calcined at $400{ }^{\circ} \mathrm{C}$ for $2 \mathrm{~h}$ at a heating rate of $2{ }^{\circ} \mathrm{C} / \mathrm{min}$. Finally, mesoporous NiO hierarchical nanomaterials with multi-morphologies were obtained.

\subsection{Sample Characterization}

X-ray diffraction (XRD, Rigaku MiniFlex II, Rigaka, Tokyo, Japan) was used to characterize the phase structure of the synthesized precursor and its calcined products, using $\mathrm{Cu} K \alpha$ radiation $(\lambda=0.15406 \mathrm{~nm})$ as the $X$-ray source. Scanning electron microscopy (SEM, JEOL JSM-6700-F, JEOL, Tokyo, Japan) was adopted to observe the morphology of the samples. Transmission electron microscopy (TEM, JEM-2010, JEOL, Tokyo, Japan) was used to observe the microstructure and morphology of the samples. X-ray photoelectron spectroscopy (XPS, ESCA-LABM250XI, Waltham, MA, USA) was used to characterize the composition and chemical valence of the NiO sample. The surface area and porosity analyzer (ASAP2460, Micromeritics, Norcross, GA, USA) was used to study the specific surface area and pore size distribution of the samples by the Brunauer-Emmett-Teller (BET) and Barrett-Joyner-Halenda (BJH) models, respectively. 


\subsection{Catalytic Role Study}

The catalytic role of $\mathrm{NiO}$ additive was evaluated by comparing the thermal decomposition behavior of AP with and without $\mathrm{NiO}$ additives. The experiment was carried on a differential thermal analyzer (DTA, Netzsch Model STA449F3). During the experimental process, $5 \mathrm{mg}$ of mixture of AP $\left(98 \mathrm{wt} \%\right.$ ) and $\mathrm{NiO}$ additive ( $2 \mathrm{wt} \%$ ) or pure $\mathrm{AP}$ was placed into an open $\mathrm{Al}_{2} \mathrm{O}_{3}$ crucible and heated in nitrogen atmosphere with a heating rate of $15^{\circ} \mathrm{C} / \mathrm{min}$ among the temperature range of $30-550{ }^{\circ} \mathrm{C}$.

\section{Results and Discussion}

\subsection{Characteriziaton of Phase Structure and Microstructure}

The phase structure and morphology of the as-prepared precursors were characterized by XRD and SEM, respectively, as shown in Figure 1. Figure 1a shows the XRD results of as-prepared precursors. When the ratio of $\mathrm{Ni}^{2+} / \mathrm{HMT}$ is $2: 1$ and 1:2, all the diffraction peaks of the precursor can be indexed as $\mathrm{Ni}_{3}\left(\mathrm{NO}_{3}\right)_{2}(\mathrm{OH})_{4}$ phase by JCPDS (Joint Committee on Powder Diffraction Standards) card (No. 22-0752) [22]. When the ratio of $\mathrm{Ni}^{2+} / \mathrm{HMT}$ is 1:3, the diffraction peaks of the precursor can be indexed to $\mathrm{Ni}\left(\mathrm{HCO}_{3}\right)_{2}$ phase (JCPDS card No. 15-0782) [23]. Figure $1 \mathrm{~b}-\mathrm{d}$ show the SEM images of the as-prepared precursors. It can be seen that when the ratio of $\mathrm{Ni}^{2+} / \mathrm{HMT}$ is $2: 1$, the product consists of many nanosheets with an average width of about $1 \mu \mathrm{m}$; when the ratio of $\mathrm{Ni}^{2+} / \mathrm{HMT}$ is $1: 2$, the product is composed of microspheres with a size of $3-5 \mu \mathrm{m}$; when the ratio of $\mathrm{Ni}^{2+} / \mathrm{HMT}$ is 1:3, the product aggregates 100-200 nm of sub-microspheres. In short, the precursors of $\mathrm{Ni}_{3}\left(\mathrm{NO}_{3}\right)_{2}(\mathrm{OH})_{4}$ nanosheets, $\mathrm{Ni}_{3}\left(\mathrm{NO}_{3}\right)_{2}(\mathrm{OH})_{4}$ microspheres, and $\mathrm{Ni}\left(\mathrm{HCO}_{3}\right)_{2}$ sub-microspheres are obtained by adjusting the ratio of $\mathrm{Ni}^{2+} / \mathrm{HMT}$ from 2:1 to 1:2 or 1:3 by our synthesis method.
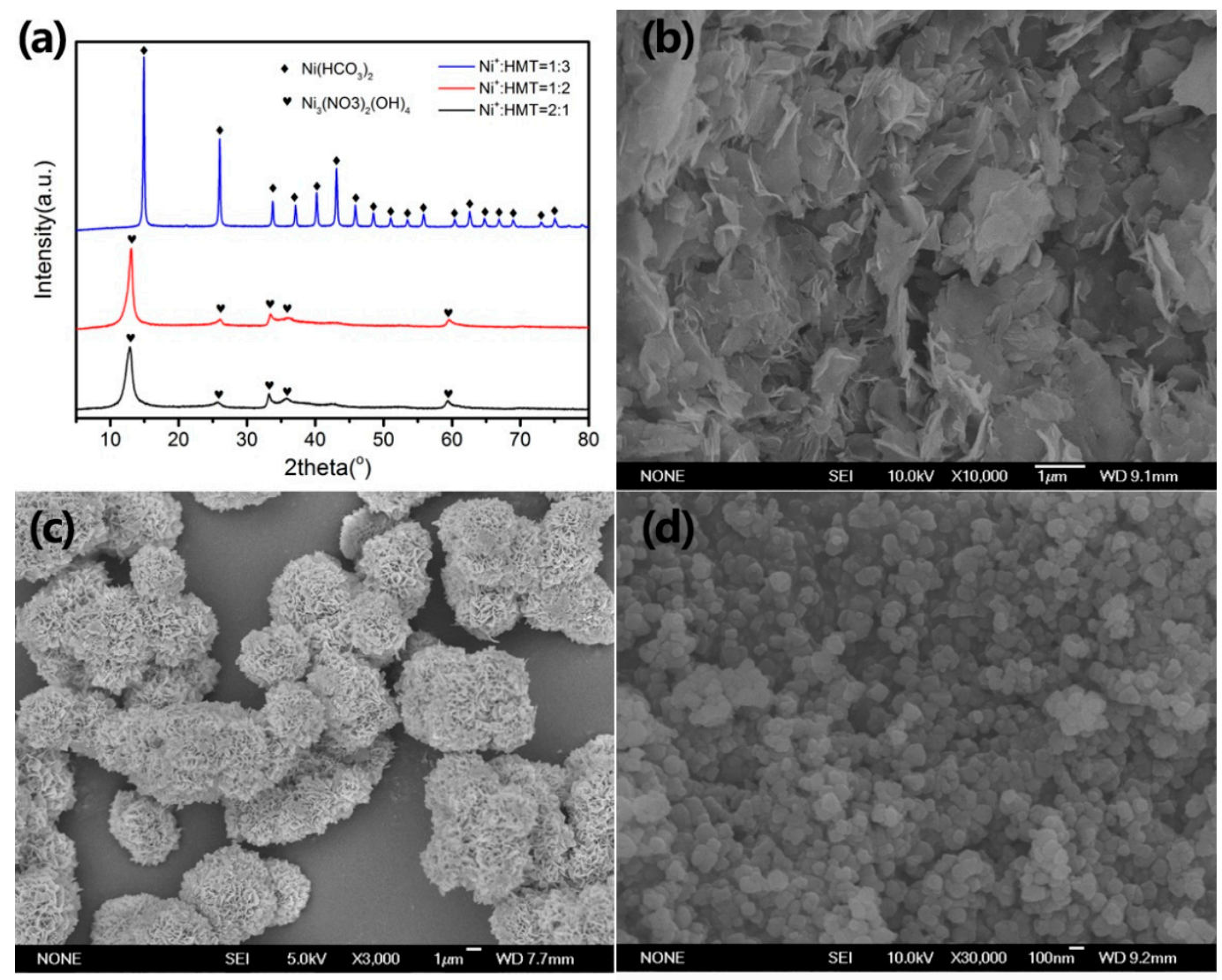

Figure 1. (a) $\mathrm{XRD}(\mathrm{Cu} \mathrm{K} \alpha, \lambda=0.15406 \mathrm{~nm}$ ) patterns and SEM (secondary electron imaging mode) images of as-prepared precursor obtained by different ratios of $\mathrm{Ni}^{2+} / \mathrm{HMT}$ (hexamethylenetetramine): (b) $2: 1$; (c) 1:2; and (d) 1:3. 
The precursors were calcined at $400{ }^{\circ} \mathrm{C}$ for $2 \mathrm{~h}$ to obtain the $\mathrm{NiO}$ samples. Figure 2 shows the $\mathrm{XRD}$ and SEM images of the calcined samples. It can be seen from Figure 2a that the calcined products were well indexed to the NiO phase (JCPDS card No. 47-1049) [24], and no impurity phases such as $\mathrm{Ni}$ and $\mathrm{Ni}(\mathrm{OH})_{2}$ were found. It indicates that the precursor was transformed into pure $\mathrm{NiO}$ phase after calcination. Figure $2 \mathrm{~b}-\mathrm{d}$ show SEM images of as-prepared $\mathrm{NiO}$ samples. By comparing the morphology of precursors in Figure $1 b-d$, it is obvious that the morphologies of $\mathrm{NiO}$ samples are basically the same as the overall morphologies of the corresponding precursors, which indicates the good structure stability of the materials during calcination. Therefore, NiO nanosheets, microspheres, and sub-microspheres were successfully prepared by calcining precursors.
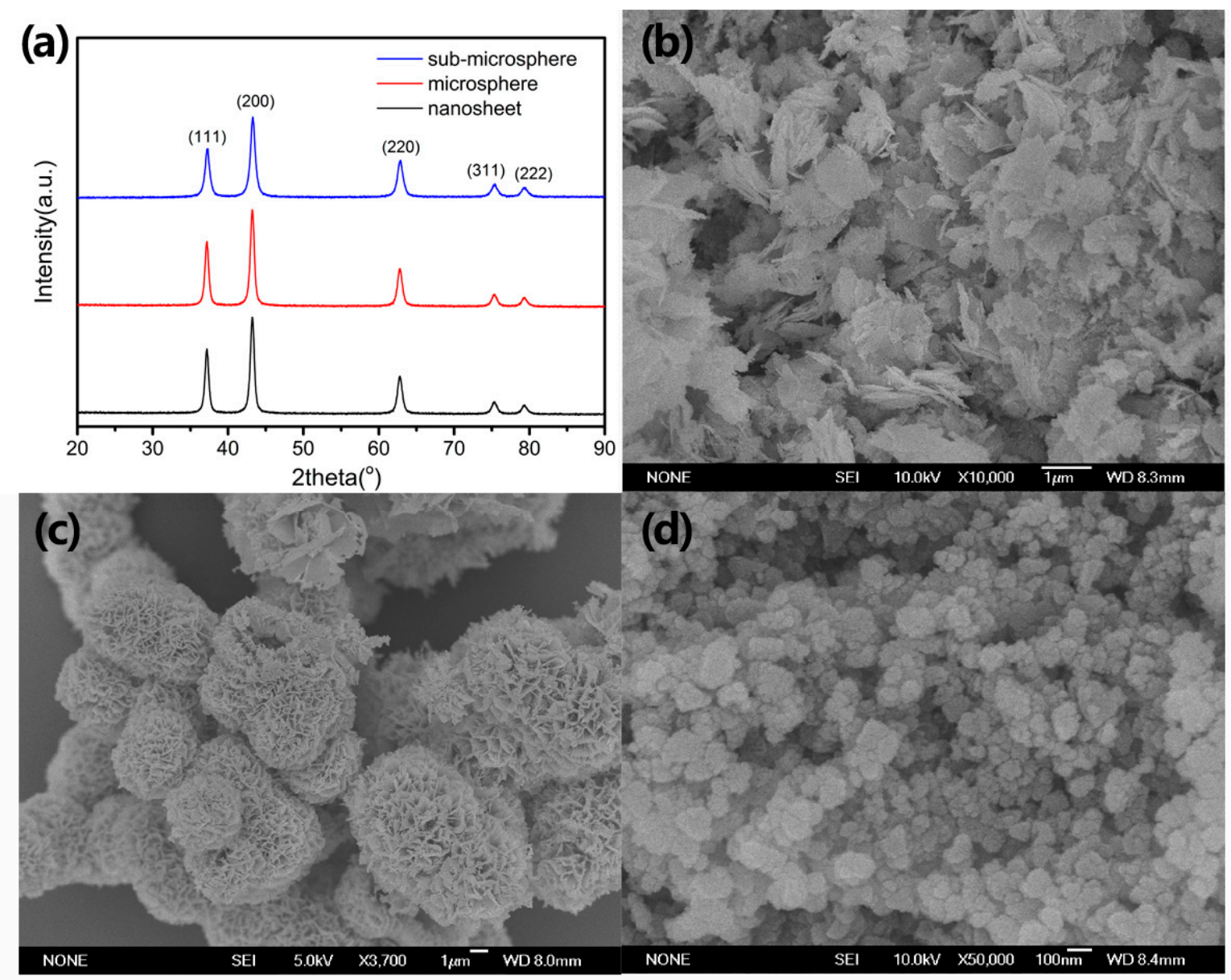

Figure 2. (a) $\mathrm{XRD}(\mathrm{Cu} \mathrm{K} \alpha, \lambda=0.15406 \mathrm{~nm})$ patterns and SEM images (secondary electron imaging mode) of as-prepared (b) nickel oxide ( $\mathrm{NiO}$ ) nanosheet; (c) $\mathrm{NiO}$ microsphere; and (d) NiO sub-microsphere.

In order to further study the morphology and microstructure of the NiO samples, TEM, high-resolution TEM (HRTEM), and selected area electron diffraction (SAED) patterns were performed and the results are shown in Figure 3. It can be seen from Figure 3a that the NiO nanosheet sample was composed of an aggregation of nanosheets, in accordance with the SEM observation (Figure 2b). The nanosheets are composed of many grains with diameters of $30-50 \mathrm{~nm}$, and a large number of holes are also observed (Figure $3 b$ ). The SAED pattern exhibits a typical polycrystalline ring, which indicates that the material has good crystallinity (inset in Figure 3b). The HRTEM image (Figure 3c) demonstrates clear crystal lattice fringes with lattice spacing of $0.208 \mathrm{~nm}$, corresponding to the (200) crystal plane of the $\mathrm{NiO}$ phase. Figure $3 \mathrm{~d}$ indicates that the $\mathrm{NiO}$ microsphere sample was composed of about $2 \mu \mathrm{m}$ microspheres and some fragmented aggregates with the size of $500 \mathrm{~nm}$ which could be caused by the ultrasonic vibration during the TEM sample preparation process. Figure 3 e shows that the microsphere 
consists of rod-like particles with a diameter of $20 \mathrm{~nm}$ and a length of $100 \mathrm{~nm}$. The SAED pattern also indicates a typical polycrystalline ring (inset in Figure 3e). The clear lattice fringes observed in HRTEM images (Figure $3 \mathrm{f}$ ) indicate the good crystallinity of the $\mathrm{NiO}$ microsphere sample. Figure $3 \mathrm{~g}$ shows that there are many aggregations of sub-microspheres with a size of $100 \mathrm{~nm}$ in the $\mathrm{NiO}$ sub-microspheres. The high-magnification TEM image in Figure $3 \mathrm{~h}$ indicates that the sub-microspheres are composed of many grains of $10-20 \mathrm{~nm}$ in size and a large number of well-distributed pores are observed. The SAED pattern is also a polycrystalline ring (inset in Figure 3h). The HRTEM image (Figure 3i) shows clear lattice fringes with a spacing of $0.244 \mathrm{~nm}$, which can be attributed to the (111) crystal plane of the $\mathrm{NiO}$ phase. The corresponding energy dispersive spectroscopy (EDS) spectra (Figure S1) indicates that the atomic ratio of $\mathrm{Ni}$ and $\mathrm{O}$ in the samples are close to 1:1.

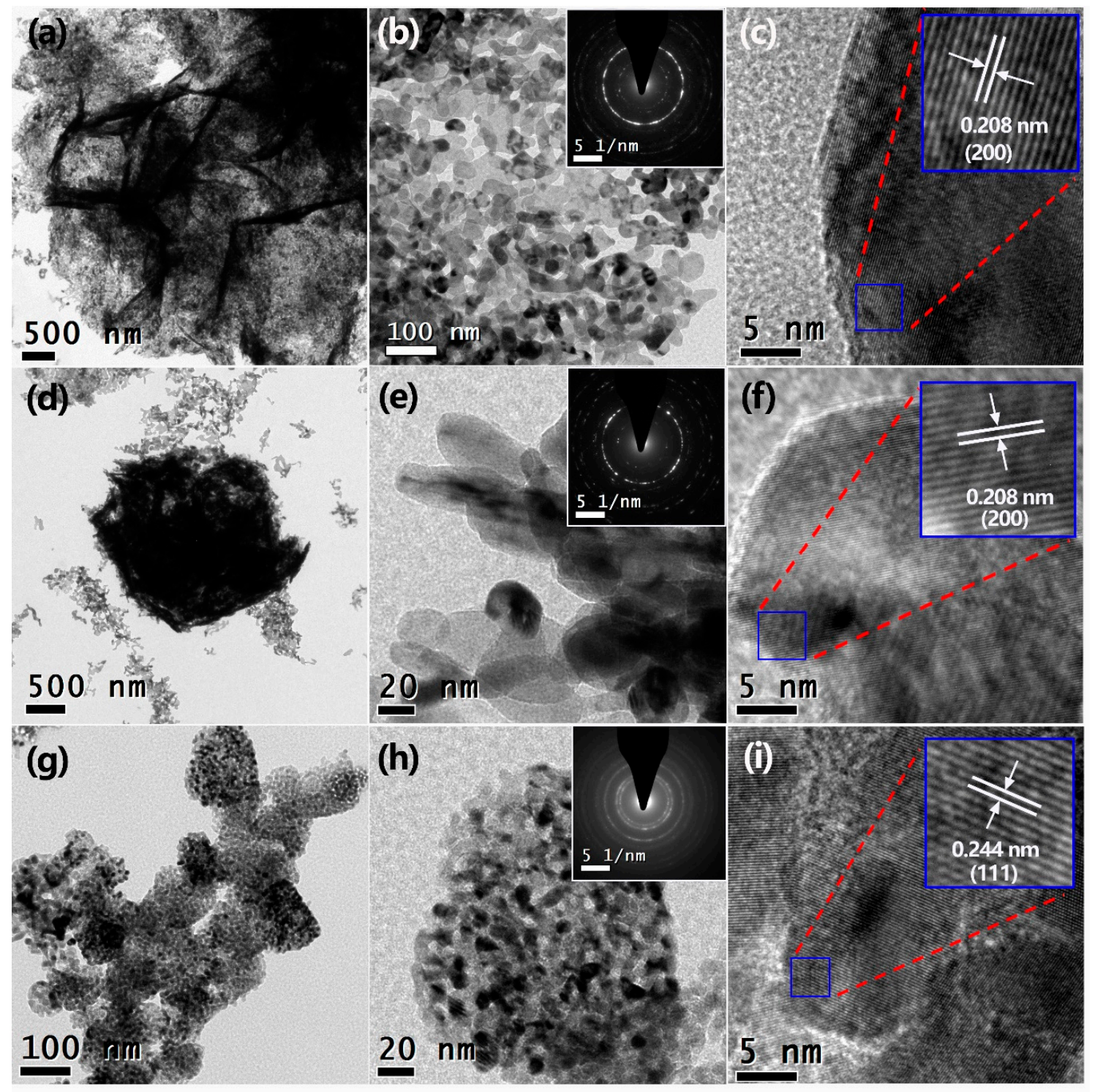

Figure 3. TEM and HRTEM images of as-prepared $\mathrm{NiO}$ nanostructures: (a) low-magnification TEM image, (b) high-magnification TEM image, and (c) HRTEM image of NiO nanosheet; (d) low-magnification TEM image, (e) high-magnification TEM image, and (f) HRTEM image of NiO microspheres; (g) low-magnification TEM image, (h) high-magnification TEM image, and (i) HRTEM image of $\mathrm{NiO}$ sub-microsphere. The insets in (b), (e), and (h) show the corresponding selected area electron diffraction (SAED) patterns. 
To study the element composition and valence state of NiO sub-microsphere sample, XPS technique was performed (Figure 4). From the survey spectrum (Figure 4a), it can be seen that the binding energy peaks of $\mathrm{Ni}$ and $\mathrm{O}$ atoms exist in the spectrum. Figure $4 \mathrm{~b}$ shows the $\mathrm{Ni} 2 \mathrm{p}$ binding energy spectrum. There are eight fitted binding energy peaks in the range of 850-885 ev. Among them, the two peaks located at 853.4 and $855.3 \mathrm{eV}$ correspond to the characteristic peaks of $\mathrm{Ni} 2 \mathrm{p} 3 / 2$, and the two peaks around 870.7 and $872.7 \mathrm{eV}$ correspond to the Ni $2 \mathrm{p} 1 / 2$ peak. The doublet peaks of 853.4 and $870.7 \mathrm{eV}$ are related with $\mathrm{Ni}^{2+}$ component, and the peaks of 855.3 and $872.7 \mathrm{eV}$ are ascribed to $\mathrm{Ni}^{3+}$ component [25]. The remaining four characteristic peaks at $860.6,864.7,877.9$, and $880.9 \mathrm{eV}$ are satellite peaks. Figure $4 \mathrm{c}$ shows the O1s binding energy spectrum. It can be fitted to three characteristic peaks of 529.2, 530.9, and $532.1 \mathrm{eV}$, which correspond to $\mathrm{Ni}-\mathrm{O}$ bond, oxygen in $\mathrm{OH}^{-}$groups, and adsorbed water on the surface of the sample, respectively. These results indicate the formation of $\mathrm{NiO}$ phase, which is consistent with XRD results.
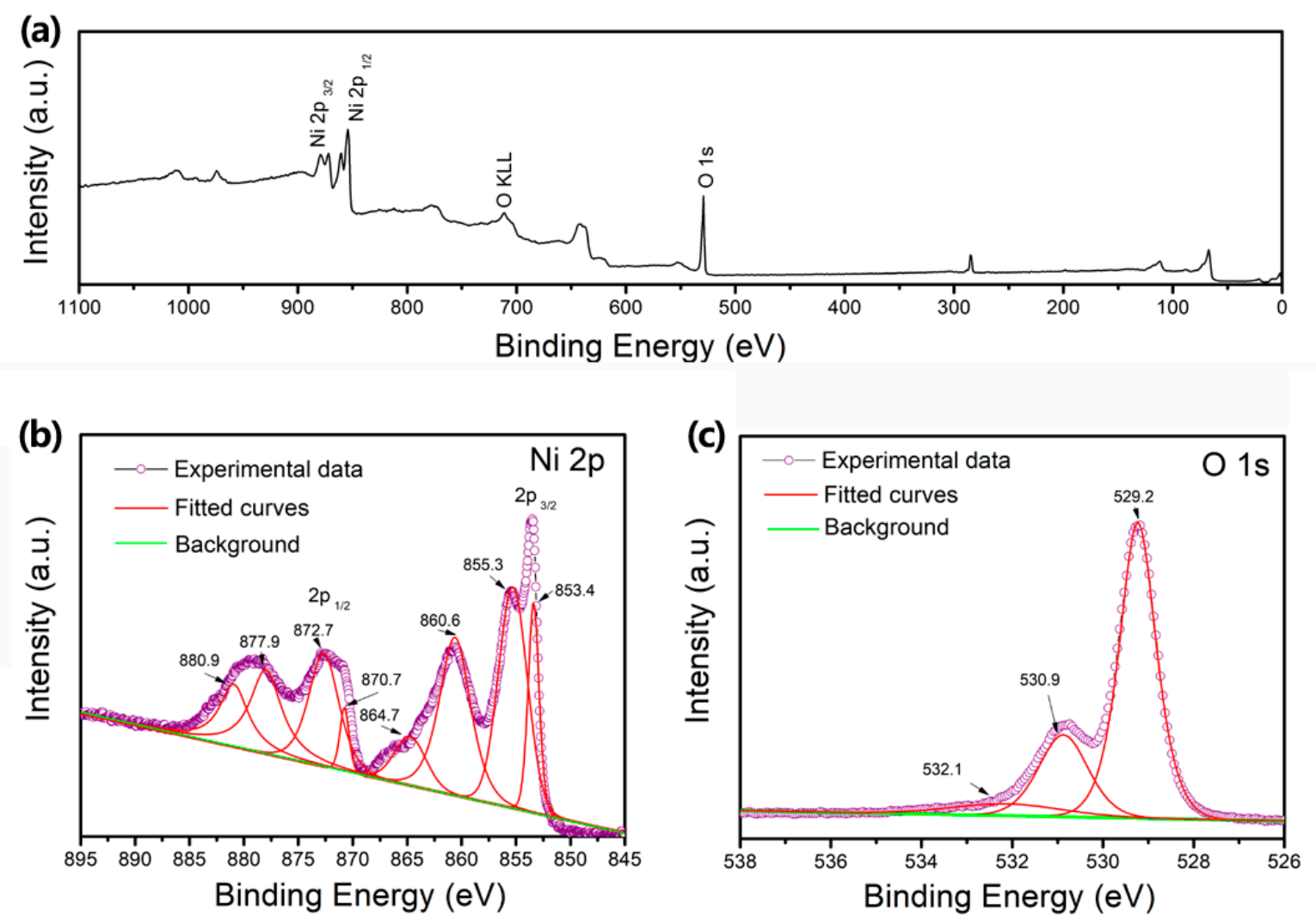

Figure 4. X-ray photoelectron spectroscopy (XPS) spectrum of as-prepared $\mathrm{NiO}$ sub-microsphere: (a) survey spectrum; (b) Ni 2p spectrum; and (c) O 1s spectrum.

Since porosities were observed in the $\mathrm{NiO}$ samples by TEM observation, the surface area and pore structure of the $\mathrm{NiO}$ samples were further investigated and the results are shown in Figure 5. The $\mathrm{N}_{2}$ adsorption-desorption isotherm curve (Figure $5 \mathrm{a}$ ) of the NiO nanosheet sample shows a typical IV type isotherm with a $\mathrm{H} 2$ hysteresis loop [26], which indicates the existence of a mesoporous structure in the sample. The BET surface area and pore volume are $40.5 \mathrm{~m}^{2} / \mathrm{g}$ and $0.11 \mathrm{~cm}^{3} / \mathrm{g}$, respectively. The $\mathrm{NiO}$ microsphere sample exhibits a similar isotherm curve (Figure $5 \mathrm{~b}$ ), with the BET surface area of $19.8 \mathrm{~m}^{2} / \mathrm{g}$ and pore volume of $0.06 \mathrm{~cm}^{3} / \mathrm{g}$. Figure $5 \mathrm{c}$ shows $\mathrm{N}_{2}$ adsorption-desorption isotherm curve of the $\mathrm{NiO}$ sub-microsphere sample. It can be seen that the enclosure area increases obviously though the same IV type isotherm with a $\mathrm{H} 2$ hysteresis loop is observed. The BET surface area and pore volume are $89.5 \mathrm{~m}^{2} / \mathrm{g}$ and $0.58 \mathrm{~cm}^{3} / \mathrm{g}$, respectively. Figure $5 \mathrm{~d}$ shows the pore size distribution derived from the adsorption branches of the isotherm data in Figure $5 \mathrm{a}-\mathrm{c}$ of the NiO samples. A peak centered at 
about $3 \mathrm{~nm}$ was observed in the $\mathrm{NiO}$ nanosheet and microsphere samples. Comparatively, three peaks located at 9, 15, and $30 \mathrm{~nm}$ are observed in the $\mathrm{NiO}$ sub-microsphere sample, as well as the apparently increased peak intensity. From the above results, it can be concluded that the $\mathrm{NiO}$ sub-microspheres sample has the largest specific surface area and pore volume, which could be related to the smallest grain size of the NiO sub-microsphere sample, as observed in the TEM results (Figure 3).
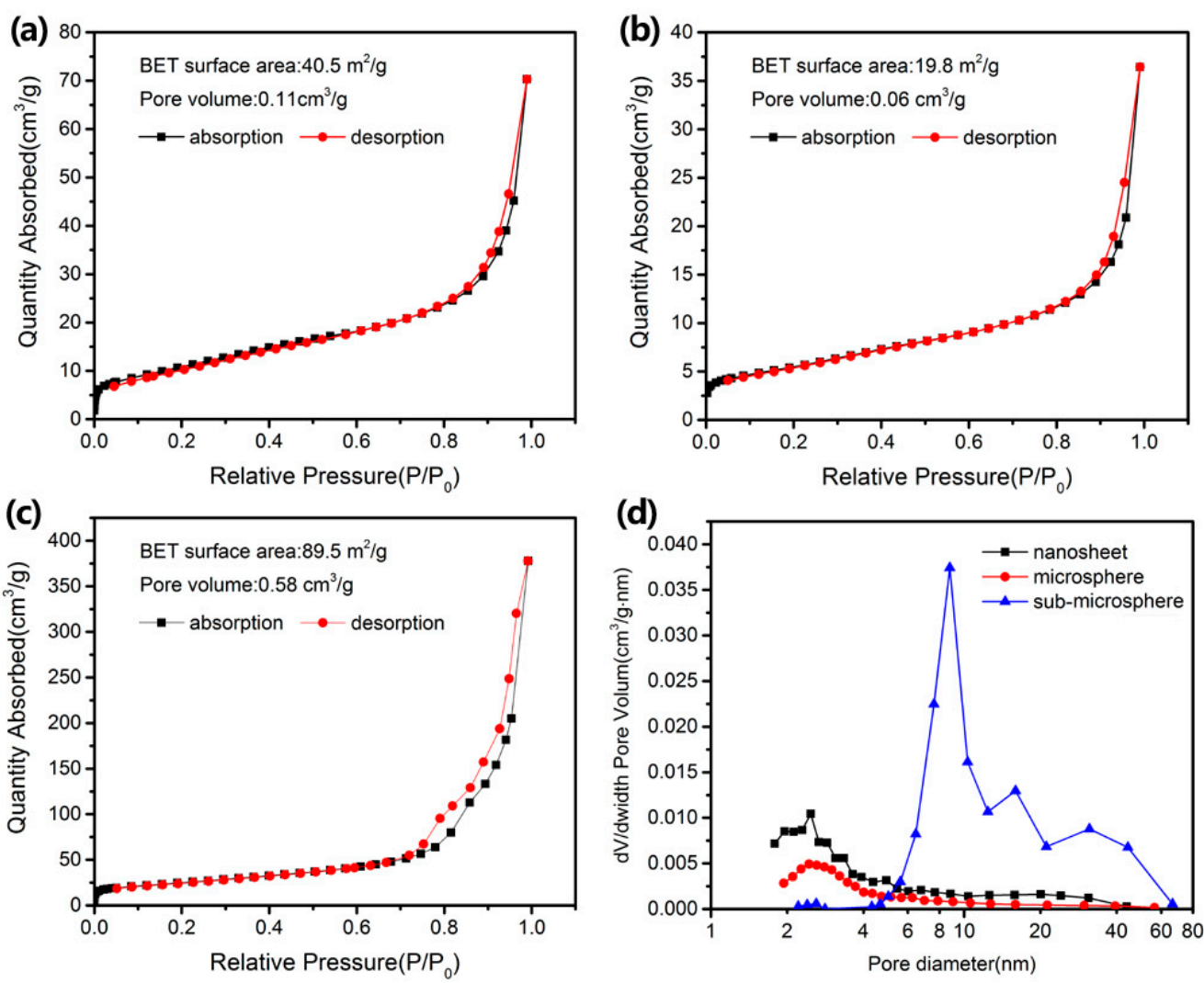

Figure 5. (a) $\mathrm{N}_{2}$ adsorption-desorption isotherm curves of $\mathrm{NiO}$ nanosheet; (b) $\mathrm{N}_{2}$ adsorption-desorption isotherm curves of $\mathrm{NiO}$ microsphere; (c) $\mathrm{N}_{2}$ adsorption-desorption isotherm curves of $\mathrm{NiO}$ sub-microsphere; and (d) pore size distribution derived from the adsorption branches of the isotherm data of the as-prepared $\mathrm{NiO}$ nanostructures.

Combined with the above results, the synthesis route of mesoporous $\mathrm{NiO}$ hierarchical nanostructures can be summarized in Figure 6. By adjusting the ratio of $\mathrm{Ni}^{2+} / \mathrm{HMT}$, the precursor with multi-morphologies can be obtained. When the ratios of $\mathrm{Ni}^{2+} / \mathrm{HMT}$ were 2:1 and 1:2, $\mathrm{Ni}_{3}\left(\mathrm{NO}_{3}\right)_{2}(\mathrm{OH})_{4}$ nanosheet and microsphere were obtained. Being calcined, they decomposed to the $\mathrm{NiO}$ phase and by-product gases such as $\mathrm{NO}_{2}, \mathrm{H}_{2} \mathrm{O}$, and $\mathrm{O}_{2}$ by the following reaction [26]:

$$
\mathrm{Ni}_{3}\left(\mathrm{NO}_{3}\right)_{2}(\mathrm{OH})_{4} \rightarrow 3 \mathrm{NiO}+2 \mathrm{NO}_{2}(\mathrm{~g})+2 \mathrm{H}_{2} \mathrm{O}(\mathrm{g})+\frac{1}{2} \mathrm{O}_{2}(\mathrm{~g})
$$

When the ratio of $\mathrm{Ni}^{2+} / \mathrm{HMT}$ was 1:3, $\mathrm{Ni}\left(\mathrm{HCO}_{3}\right)_{2}$ sub-microsphere was obtained, which decomposed to the $\mathrm{NiO}$ phase and gases of $\mathrm{H}_{2} \mathrm{O}$ and $\mathrm{CO}_{2}$ by the following reaction [27]:

$$
\mathrm{Ni}\left(\mathrm{HCO}_{3}\right)_{2} \rightarrow \mathrm{NiO}+\mathrm{H}_{2} \mathrm{O}(\mathrm{g})+2 \mathrm{CO}_{2}(\mathrm{~g})
$$




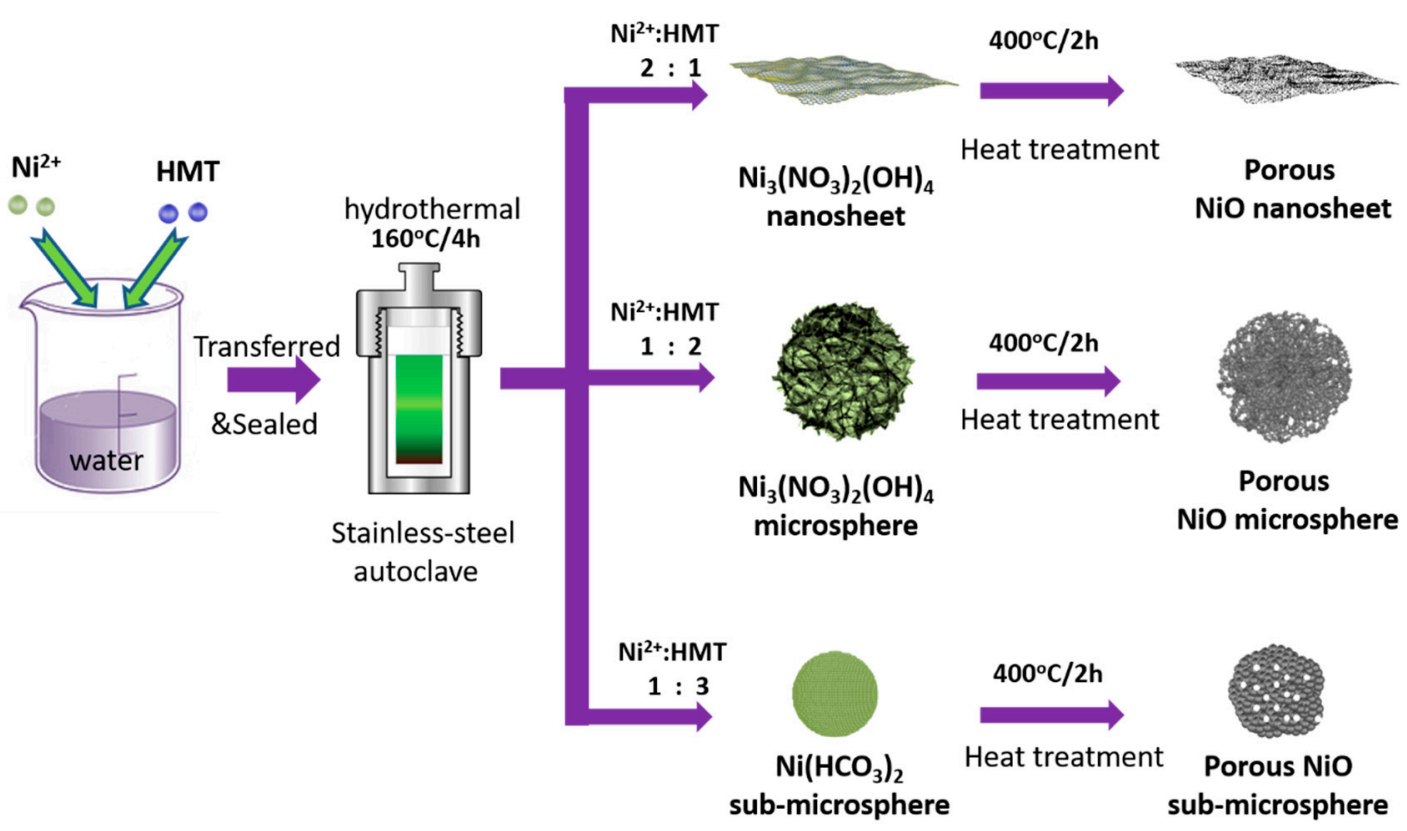

Figure 6. The synthesis route of hydrothermal reaction and subsequent calcination for mesoporous $\mathrm{NiO}$ hierarchical nanostructures.

The released by-product gases lead to the formation of a mesoporous structure in the $\mathrm{NiO}$ samples. To prove that the mesoporous structure was formed by calcination, the microstructure of an uncalcined microsphere precursor was studied by TEM, as shown in Figure S2. It clearly indicates the absence of mesoscale porosities in the uncalcined microsphere precursor. Thus, the calcination is helpful to the formation of the mesoporous structure.

\subsection{Catalytic Role of $\mathrm{NiO}$ Addtives}

Ammonium perchlorate (AP) is an important oxidant commonly used in rocket solid composite propellant. Its catalyzed thermal decomposition plays a key role in satellite launching and space exploration. The core part of catalyzed thermal decomposition of AP is the additives that can promote $\mathrm{AP}$ to achieve highly concentrated thermal decomposition at lower temperatures. The thermal decomposition of AP can be divided into two stages. One stage is usually in the range of $290-330{ }^{\circ} \mathrm{C}$, which is called the low temperature decomposition (LTD) stage. The other stage occurs in the range of 350-450 ${ }^{\circ} \mathrm{C}$ and is called the high temperature decomposition (HTD) stage [28]. In the LTD stage, AP decomposes into $\mathrm{NH}_{3}$ and $\mathrm{HClO}_{4}$. The excess $\mathrm{NH}_{3}$ continuously adsorbs on the AP surface to stop the LTD stage. When the temperature increases further, $\mathrm{NH}_{3}$ adsorbed on the AP surface will desorb from the AP surface, and then the HTD of AP begins.

The catalytic role of as-prepared mesoporous $\mathrm{NiO}$ nanomaterials towards $\mathrm{AP}$ thermal decomposition was evaluated by the DTA technique. Figure 7a shows the DTA curves of pure $\mathrm{AP}$ and $\mathrm{AP}$ mixtures with $\mathrm{NiO}$ nanomaterials as additives. For pure $\mathrm{AP}$, there is an endothermic peak at $248.8^{\circ} \mathrm{C}$ and two exothermic peaks at 337.8 and $461.4^{\circ} \mathrm{C}$. Previous studies have shown that the endothermic peak at $248.8^{\circ} \mathrm{C}$ corresponds to the transition temperature of AP from the rhombic phase to the cubic phase; the exothermic peak at $337.8^{\circ} \mathrm{C}$ is associated with the LTD temperature $\left(\mathrm{T}_{\mathrm{a}}\right)$ of $\mathrm{AP}$, and the exothermic peak at $461.4^{\circ} \mathrm{C}$ is ascribed to the HTD temperature $\left(\mathrm{T}_{\mathrm{b}}\right)$ of AP. After adding $\mathrm{NiO}$ nanomaterials as additives, the DTA curve of the AP mixture has changed obviously. The phase transition temperature of AP did not change after adding $\mathrm{NiO}$ additives, which indicates that $\mathrm{NiO}$ additives have no effect on the phase transition temperature of AP [29]. Additionally, the intensity and area of the exothermic peak are obviously increased though the LTD temperatures of AP are slightly decreased. The HTD temperatures of AP are obviously decreased, and the exothermic peaks at a higher 
temperature are weakened. It indicates that the $\mathrm{NiO}$ additives have an obvious catalytic role towards the thermal decomposition of AP.
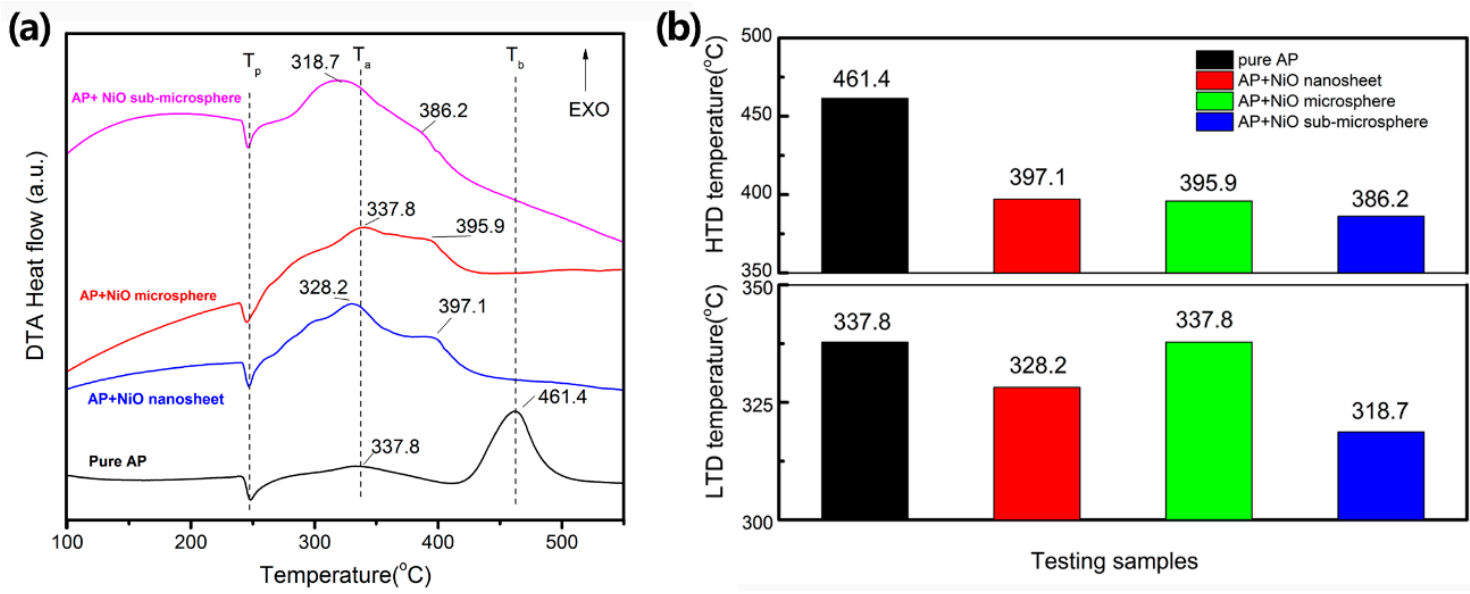

Figure 7. (a) Differential thermal analyzer (DTA) curves of pure ammonium perchlorate (AP) and AP mixture with as-prepared $\mathrm{NiO}$ additives; (b) histogram of high temperature decomposition (HTD) and low temperature decomposition (LTD) temperatures in (a).

In order to further study the catalytic effects, the LTD temperatures and HTD temperatures of different samples are compared, as shown in Figure $7 \mathrm{~b}$. It can be seen that $\mathrm{NiO}$ sub-microspheres exhibit the best catalytic role among all samples, which can reduce the HTD temperature of AP from 461.4 to $386.2{ }^{\circ} \mathrm{C}$ and the LTD temperate from 337.8 to $318.7^{\circ} \mathrm{C}$, respectively. It indicates that the HTD and LTD temperature of AP can be decreased by 75.2 and $19.1^{\circ} \mathrm{C}$. The catalytic activity of NiO sub-microsphere toward AP thermal decomposition is much better than the commercial spectrograde $\mathrm{NiO}$ reported by Wang et al. [29] with an HTD temperature of $412{ }^{\circ} \mathrm{C}$. Although the mechanism of AP thermal decomposition is complex, we believe that the superior catalytic role of $\mathrm{NiO}$ sub-microsphere should be related to their large specific surface area, pore volume, and small grain size, which can facilitate gas diffusion and provide more reactive sites.

\section{Conclusions}

In this paper, mesoporous $\mathrm{NiO}$ hierarchical nanomaterials were prepared by a facile hydrothermal method and subsequent calcination. By adjusting the ratio of $\mathrm{Ni}^{2+} / \mathrm{HMT}$, the precursors of $\mathrm{Ni}_{3}\left(\mathrm{NO}_{3}\right)_{2}(\mathrm{OH})_{4}$ nanosheet, $\mathrm{Ni}_{3}\left(\mathrm{NO}_{3}\right)_{2}(\mathrm{OH})_{4}$ microsphere, and $\mathrm{Ni}\left(\mathrm{HCO}_{3}\right)_{2}$ sub-microsphere were prepared. After calcination at $400{ }^{\circ} \mathrm{C}$ for $2 \mathrm{~h}$, the precursors can be transformed to mesoporous $\mathrm{NiO}$ nanosheet, microsphere, and sub-microsphere. When used as additives for AP thermal decomposition, the as-prepared $\mathrm{NiO}$ nanomaterials showed an obvious catalytic role. Among them, $\mathrm{NiO}$ sub-microspheres have the best catalytic role, which reduces the HTD and LTD temperature by 75.2 and $19.1{ }^{\circ} \mathrm{C}$, respectively. Therefore, the synthetic route adopted in this paper can rapidly prepare mesoporous $\mathrm{NiO}$ hierarchical nanomaterials, which can be used as AP thermal decomposition additives.

Supplementary Materials: The following are available online at http://www.mdpi.com/2076-3417/9/13/2599/s1, Figure S1: EDS spectrum of (a) $\mathrm{NiO}$ nanosheet; (b) NiO sub-microsphere, Figure S2: (a) Low-magnification TEM image, (b) high-magnification TEM image; and (c) HRTEM image of the precursor of $\mathrm{Ni}_{3}\left(\mathrm{NO}_{3}\right)_{2}(\mathrm{OH})_{4}$ microsphere.

Author Contributions: S.Y. performed the experiments and wrote the paper; X.G. conceived and designed the experiments, analyzed the data, and revised the paper.

Funding: This work was funded by Natural Science Foundation of Fujian Province (2017J01676), the Key Research Foundation for Young Scholars of Fujian Education Department of China (JZ160486), and the Program for New Century Excellent Talents in Fujian Province University (Minjiaoke (2018) No. 47).

Conflicts of Interest: The authors declare no conflicts of interest. 


\section{References}

1. Poizot, P.; Laruelle, S.; Grugeon, S.; Dupont, L.; Tarascon, J.M. Nano-sized transition-metal oxides as negative-electrode materials for lithium-ion batteries. Nature 2000, 407, 496-499. [CrossRef] [PubMed]

2. Macdonald, T.J.; Xu, J.; Elmas, S.; Mange, Y.J.; Skinner, W.M.; Xu, H.L.; Nann, T. NiO nanofibers as a candidate for a nanophotocathode. Nanomaterials 2014, 4, 256-266. [CrossRef] [PubMed]

3. Zhao, J.B.; Wu, L.L.; Zou, K. Fabrication of hollow mesoporous NiO hexagonal microspheres via hydrothermal process in ionic liquid. Mater. Res. Bull. 2011,46, 2427-2432. [CrossRef]

4. Zhang, L.; Liu, P.F.; Li, Y.H.; Zu, M.Y.; Li, X.; Jiang, Z.; Wang, Y.; Zhao, H.; Yang, H.G. N-modified NiO surface for superior alkaline hydrogen evolution. ChemSusChem 2018, 11, 1020-1024. [CrossRef] [PubMed]

5. Wei, W.X.; Jiang, X.H.; Lu, L.D.; Yang, X.J.; Wang, X. Study on the catalytic effect of NiO nanoparticles on the thermal decomposition of TEGDN/NC propellant. J. Hazard. Mater. 2009, 168, 838-842. [CrossRef] [PubMed]

6. Luan, V.H.; Tien, H.N.; Hur, S.H.; Han, J.H.; Lee, W. Three-dimensional porous nitrogen-doped NiO nanostructures as highly sensitive $\mathrm{NO}_{2}$ sensors. Nanomaterial 2017, 7, 313. [CrossRef] [PubMed]

7. Kumar, J.P.; Giri, S.D.; Sarkar, A. Mesoporous NiO with different morphology: Synthesis, characterization and their evaluation for oxygen evolution reaction. Int. J. Hydrogen Energy 2018, 43, 15639-15649. [CrossRef]

8. Yan, X.Y.; Tong, X.L.; Wang, J.; Gong, C.W.; Zhang, M.G.; Liang, L.P. Synthesis of mesoporous NiO nanoflake array and its enhanced electrochemical performance for supercapacitor application. J. Alloy Compd. 2014, 593, 184-189. [CrossRef]

9. Shenashen, M.A.; Kawada, S.; Selim, M.M.; Morsy, W.M.; Yamaguchi, H.; Alhamid, A.A.; Ohashi, N.; Lchinose, I.; El-Safty, S.A. Bushy sphere dendrites with husk-shaped branches axially spreading out from the core for photo-catalytic oxidation/remediation of toxins. Nanoscale 2017, 9, 7947-7959. [CrossRef]

10. Emran, M.Y.; Mekawy, M.; Akhtar, N.; Shenashen, M.A.; EL-Sewify, I.M.; Faheem, A.; El-Safty, S.A. Broccoli-shaped biosensor hierarchy for electrochemical screening of noradrenaline in living cells. Biosens. Bioelectron. 2018, 100, 122-131. [CrossRef]

11. Emran, M.Y.; Shenashen, M.A.; Abdelwahab, A.A.; Khalifa, H.; Mekawy, M.; Akhtar, N. Design of hierarchical electrocatalytic mediator for one step, selective screening of biomolecules in biological fluid samples. J. Appl. Electrochem. 2018, 48, 529-542. [CrossRef]

12. Emran, M.Y.; Shenashen, M.A.; Mekawy, M.; Azzam, A.M.; Akhtar, N.; Gomaa, H.; Selim, M.M.; Faheem, A.; El-Safty, S.A. Ultrasensitive in-vitro monitoring of monoamine neurotransmitters from dopaminergic cells. Sens. Actuators B Chem. 2018, 259, 114-124. [CrossRef]

13. Emran, M.Y.; Khalifa, H.; Gomaa, H.; Shenashen, M.A.; Akhtar, N.; Mekawy, M.; Faheem, A.; El-Safty, S.A. Hierarchical C-N doped $\mathrm{NiO}$ with dual-head echinop flowers for ultrasensitive monitoring of epinephrine in human blood serum. Microchim. Acta 2017, 184, 4553-4562. [CrossRef]

14. Akhtar, N.; Emran, M.Y.; Shenashen, M.A.; Khalifa, H.; Osaka, T.; Faheem, A.; Homma, T.; Kawarada, H.; El-Safty, S.A. Fabrication of photo-electrochemical biosensors for ultrasensitive screening of mono-bioactive molecules: The effect of geometrical structures and crystal surfaces. J. Mater. Chem. B 2017, 5, 7985-7996. [CrossRef]

15. Liu, W.Y.; Wu, J.; Yang, Y.; Yu, H.; Dong, X.T.; Wang, X.L.; Liu, Z.L.; Wang, T.T.; Zhao, B. Facile synthesis of three-dimensional hierarchical $\mathrm{NiO}$ microflowers for efficient room temperature $\mathrm{H}_{2} \mathrm{~S}$ gas sensor. Nano J. Mater. Sci. Mater. Electron. 2018, 29, 4624-4631. [CrossRef]

16. Zhou, Q.; Lu, Z.R.; Wei, Z.J.; Xu, L.N.; Gui, Y.G.; Chen, W.G. Hydrothermal synthesis of hierarchical ultrathin $\mathrm{NiO}$ nanoflakes for high-performance $\mathrm{CH}_{4}$ sensing. Front. Chem. 2018, 6, 194. [CrossRef] [PubMed]

17. Ahirwar, D.; Bano, M.; Khan, I.; Sheikh, M.U.D.; Thomas, M.; Khan, F. Fabrication of hierarchically mesoporous $\mathrm{NiO}$ nanostructures and their role in heterogeneous photocatalysis and sensing activity. J. Mater. Sci. Mater. Electron. 2018, 29, 5768-5781. [CrossRef]

18. Zhang, H.; Chen, W.G.; Li, Y.Q.; Jin, L.F.; Cui, F.; Song, Z.H. 3D flower-like NiO hierarchical structures assembled with size-controllable 1D blocking units: Gas sensing performances towards acetylene. Front. Chem. 2018, 6, 472. [CrossRef] [PubMed]

19. Han, K.H.; Huang, H.; Gong, Q.H.; Si, T.T.; Zhang, Z.L.; Zhou, G.W. Temperature-induced hierarchical tremella-like and pinecone-like $\mathrm{NiO}$ microspheres for high-performance supercapacitor electrode materials. J. Mater. Sci. 2018, 53, 12477-12491. [CrossRef] 
20. Cai, Y.; Ma, J.M.; Wang, T.H. Hydrothermal synthesis of $\alpha-\mathrm{Ni}(\mathrm{OH})_{2}$ and its conversion to NiO with electrochemical properties. J. Alloy Compd. 2014, 582, 328-333. [CrossRef]

21. Derbalah, A.; El-safty, S.A.; Shenashen, M.A.; Khairy, M. Hierarchical nanohexagon ceramic sheet layers as platform adsorbents for hydrophilic and hydrophobic insecticides from agricultural wastewater. ChemPlusChem 2015, 80, 1769-1778. [CrossRef]

22. Shi, M.J.; Cui, M.W.; Kang, L.T.; Li, T.T.; Yun, S.; Du, J.; Xu, S.D.; Liu, Y. Porous $\mathrm{Ni}_{3}\left(\mathrm{NO}_{3}\right)_{2}(\mathrm{OH})_{4}$ nano-sheets for supercapacitors: Facile synthesis and excellent rate performance at high mass loadings. Appl. Surf. Sci. 2018, 427, 678-686. [CrossRef]

23. Wang, H.F.; Wu, L.M.; Wang, Y.S.; Li, X.N.; Wang, Y.J. Facile synthesis of Ni nanoparticles from triangular $\mathrm{Ni}\left(\mathrm{HCO}_{3}\right)_{2}$ nanosheets as catalysts for hydrogen generation from hydrous hydrazine. Catal. Commun. 2017, 100, 33-37. [CrossRef]

24. Wang, X.S.; Chen, L.; Li, F.; Zhang, S.Q.; Chen, X.C.; Yin, J.J. Synthesis of hollow NiO nanostructures and their application for supercapacitor electrode. Ionics 2018, 25, 697-705. [CrossRef]

25. Hao, C.; Zhou, S.; Wang, J.J.; Wang, X.H.; Gao, H.W.; Ge, C.W. Preparation of hierarchical spinel $\mathrm{NiCO}_{2} \mathrm{O}_{4}$ nanowires for high-performance supercapacitors. Ind. Eng. Chem. Res. 2018, 57, 2517-2525. [CrossRef]

26. Sietsma, J.R.A.; Meeldijk, J.D.; Versluijs-Helder, M.; Broersma, A.; Dillen, A.J.V.; Jongh, P.E.D.; Jong, K.P.D. Ordered mesoporous silica to study the preparation of $\mathrm{Ni} / \mathrm{SiO}_{2}$ ex nitrate catalysts: Impregnation, drying, and thermal treatments. Chem. Mater. 2008, 20, 2921-2931. [CrossRef]

27. Li, Y.W.; Zheng, Y.Y.; Yao, J.H.; Xiao, J.R.; Yang, J.W.; Xiao, S.H. Facile synthesis of nanocrystalline-assembled nest-like NiO hollow microspheres with superior lithium storage performance. RSC Adv. 2017, 7, 31287-31297. [CrossRef]

28. Sharma, J.K.; Srivastava, P.; Singh, G.; Akhtar, M.S.; Ameen, S. Biosynthesized NiO nanoparticles: Potential catalyst for ammonium perchlorate and composite solid propellants. Ceram. Inter. 2015, 41, 1573-1578. [CrossRef]

29. Wang, Y.P.; Zhu, J.W.; Yang, X.J.; Lu, L.D.; Wang, X. Preparation of NiO nanoparticles and their catalytic activity in the thermal decomposition of ammonium perchlorate. Thermochim. Acta 2005, 437, 106-109. [CrossRef]

(C) 2019 by the authors. Licensee MDPI, Basel, Switzerland. This article is an open access article distributed under the terms and conditions of the Creative Commons Attribution (CC BY) license (http://creativecommons.org/licenses/by/4.0/). 